\title{
CURRENT STATUS OF SURGERY IN THE TREATMENT OF CANCER
}

\author{
Warren H. Cole, M.D., William H. Harridge, M.D., and James Hunter, M.D. \\ From the Department of Surgery, University of Illinois College of Medicine, Chicago 12, Illinois, U.S.A.
}

MORE progress has been made in the treatment of cancer during the past $15-20$ years than in many preceding decades or centuries. Although the more dramatic advances have been made in research, progress in surgery has been commendable indeed. This progress in surgery is reflected in both phases of results: (I) a gradual decrease in mortality rate following operation, and (2) improvement in five-year survival rates following resection of the tumour. Although surgery and radiation represent the only two mechanisms offering a cure for cancer, chemotherapy is already being used as an adjuvant to surgery, and it is barely possible that principles of immunology will be utilized in the near future as an effective mechanism of therapy.

The improvement in surgical results during the past 15-20 years has been related to: (I) an increase in the amount of tissue excised with the tumour, (2) an improved knowledge of the surgical physiology resulting in better pre- and postoperative care, and (3) better anæsthesia. A study of our surgical methods and the mechanisms by which improvement can be, or will be, made, indicate rather clearly that we cannot expect additional improvement by increasing the extent of the operation since we are now excising so much adjacent tissue with the tumour that no more can be excised without removing vital structures. We must also assume that, although gradual improvements will be made in our knowledge of surgical physiology, no discovery will be made in the immediate future which will yield dramatic improvement in this field. Also, we can probably assume that anæsthesia has developed to a point where very few deaths are related to deficiencies or accidents in this field. Accordingly, it would appear that the possibility of significant improvement in the near future must rest upon the development of new principles in technique or the use of adjuvant measures.

\section{Preparation of Patient for Operation}

A thorough examination of the patient with

This work was supported in part by USPHS Grant No. 3 I 57. carcinoma is necessary because the operation for removal of the tumour is often a very formidable? one, and the patient is often elderly with many decrements. During the past io to I 5 years we have learned that elderly people will tolerate 8 operations of moderate magnitude about as well 3 . as young people, but if the operation is quite formidable and decrements or complications are present, the mortality rate will be sharply higher $\stackrel{0}{\infty}$ than in younger people in excellent condition. Accordingly, a thorough search must be made for $\vec{\sigma}$ such deficiencies as anæmia, decrease in blood $\mathrm{O}$ proteins, decrease in blood volume, and mal- $\vec{c}$ nutrition. Routine examination in such patients, particularly in men, must also include a NPN or $\bar{D}$ BUN determination. A routine examination will $\vec{\varphi}$ discover such complications as hypertensiof kidney infection, etc.

As far as possible, the decrements must corrected before the patient is subjected to a major operation for resection of his cancer. For example, anæmia and hypoproteinemia must be corrected $\frac{\varnothing}{\circ}$ with blood transfusions and administration of plasma if the protein deficiency is greater than the $\overrightarrow{\vec{O}}$ red cell deficiency. A blood volume determination should be made before operation in all patients having major operations. A single determination of blood volume is not very helpful, but determinations for a comparative purpose later become very helpful if an operation with massive blood loss and replacement has been performed in the meantime. When blood loss is massive, requiring replacement of many pints of blood, it is usually very difficult to determine whether blood replacement has been under or over the requirements.

In our estimation the most common error made by the capable surgeon at the present time is the $\mathbb{N}$ failure to recognize and correct malnutrition. N Practically all patients with gastrointestinal cancer ్ㅠ will have a loss of weight which in reality is equivalent to malnutrition. With very few exceptions a few pounds can be regained (see Fig. I). In our opinion, if the patient has lost 15 to $25 \mathrm{lb}$. we should get back 3 to $5 \mathrm{lb}$. before he is subjected 0 to a major operation. It is not essential to regain all the lost weight because a great deal of this is fat. $\stackrel{\cap}{\Omega}$ 


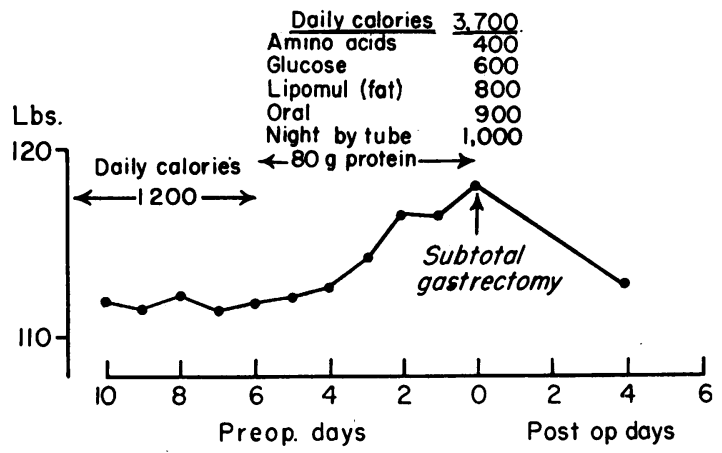

FIG. I.-This patient was a white man, aged 70, who had a carcinoma of the stomach with symptoms of six months' duration and a weight loss of $25 \mathrm{lb}$. He was put on a regime of intensive caloric intake and in five days had gained $6 \mathrm{lb}$. In addition to the caloric intake (oral and intravenous) as listed above, he was given $1,000 \mathrm{cc}$. blood before operation and I,000 cc. during operation. The serum albumin on admission was 3.7 and the globulin 2.4. Just before operation they were 4.5 and 2.2 respectively. The tumour was large, but no metastases beyond the lines of excision were present at the time of gastrectomy.

However, we must supply enough protein to allow the protein deposits to be replenished. The malnutrition is often greater in patients with oral cancer than in patients with gastrointestinal cancer because of the pain produced by chewing or swallowing. In general, patients with cancer of the oral cavity or gastrointestinal tract will not be able to eat more than 800 to 1,000 calories per day. By inserting a soft plastic tube through the patient's nose into the stomach we can usually give 800 to 1,000 calories at night while the patient is asleep. However, this combined oral and tube feeding is not sufficient to obtain a weight gain; intravenous fluid is therefore necessary. We rely upon one or two litres of 5 or $10 \%$ carbohydrate and 5\% amino acids along with 500 cc. fat (Lipomul) per day. The fat will furnish 800 additional calories, and the intravenous carbohydrates and amino acids an additional $55^{\circ}$ to $\mathrm{I}, \mathrm{I} 00$ calories. In this way, the daily caloric intake can be increased to a figure well above 3,000 and a weight gain will be rather universal unless there is an intestinal fistula, diarrhœa or some other source of nutrient loss. By these procedures it is possible to gain 4 or $5 \mathrm{lb}$. in as many days. If the surgeon's interpretation of the nutritional status is not consistent with the laboratory data such as blood proteins, we wish to emphasize that the laboratory determinations must not be misinterpreted. On some occasions the patient's 'vascular tree' appears to cling to the albumin and globulin at the expense of the vital depots when intake has been curtailed.
Often, indeed, when patients have had their intake reduced to one-half or less for several weeks the laboratory reports that blood protein levels are normal. Under such circumstances, it is rather obvious that the diminished intake should result in a protein depletion; knowing that there has been a sharp reduction in protein intake we must disregard the laboratory results, and abide by the clinical impression. Accordingly, if the history reveals a sharp reduction in caloric intake (particularly of the protein type), we should make an effort to replenish the proteins even though the blood level may be normal or near normal.

The Variability of Results in Different Tumours

We are well aware of the fact that the mortality rate following operations and the five-year survival rates of the various tumours vary tremendously. For example, the operative mortality rate for cancer of the skin is near ' $O$ ' and the five-year survival rate approaches $90 \%$. On the contrary, the operative mortality rate following radical resection for cancer of the pancreas and resection of the esophagus (Mustard, 1956) for middle third lesions varies between 15 and $25 \%$, and the fiveyear survival rate is less than $5 \%$. Fortunately, we can say that the five-year survival rate in patients with such common lesions as cancer of the breast, colon (Griffin, Judd and Gage, 1956) and rectum (Mayo and Fly, 1956) approaches 50\%. Actually, the five-year survival rate of patients having an operation for curative cancer of the stomach is much better than usually considered by those not familiar with the exact figures. Although the over-all five-year survival rate for cancer of the stomach may be no greater than 5 to $8 \%$, the five-year survival rate in patients having resection for curable cancer of the stomach will be in the neighbourhood of 25 to $50 \%$, depending upon which type of tumour is present. In malignant ulcers of the stomach, the five-year survival rate after curative resection has been reported by several authors as approaching $50 \%$, although the five-year survival rate in patients with hyperplastic cancer is no more than $25 \%$. In patients with carcinoma of the middle third of the œsophagus we (in our clinic) have not done a resection with an osophagogastrostomy above the aortic arch for at least eight years, because of the high operative mortality rate following this procedure, and the low five-year survival rate. Instead, if the tumour is resectable, we have performed a resection through the thorax, turning in the end of the distal œsophagus and bringing out the proximal end through the neck. At a later date we bring the right colon up to act as a conduit for food between the stump of the œsophagus and the stomach.

In lesions located at the terminal end of the 
common duct we must differentiate accurately between carcinoma at the head of the pancreas and the ampulla of Vater because the five-year survival rate of patients having radical resection for carcinoma of the ampulla of Vater is $25 \%$, but less than $5 \%$ for carcinoma of the head of the pancreas. It will often be necessary to open the duodenum and inspect the ampulla of Vater in patients having lesions in this area.

\section{The Extent of Operation}

There is considerable controversy concerning the amount of normal tissue to be removed with the tumour. Actually this will vary with different tumours. Perhaps the greatest difference of opinion lies in the decision concerning the amount of resected normal tissue with carcinoma of the colon and stomach. Some surgeons do a high subtotal gastrectomy or total gastrectomy for all carcinomas of the stomach and often make splenectomy routine with this procedure. Likewise, some surgeons will do almost a total colectomy with anastomosis of the crcum to the rectum for most carcinomas of the colon. This is contrasted to a minimal resection which a few surgeons believing in 'predeterminism' would advise. Most surgeons recommend a ' middle of the road' type of resection on the basis that a minimal resection will not remove tumour in adjacent lymphatics or veins, and that the use of the ultra-radical procedure will not justify its utilization because the increase in operative mortality rate more than neutralizes the improvement in the five-year survival rate. However, this question. of the amount of tumour to be removed with a given tumour is by no means completely resolved; accordingly, more work must be done on this problem.

\section{The Role of Early Diagnosis in Results}

Unfortunately, we are still seeing patients who do not come to the physician for several months after symptoms of their cancer have begun. In such patients the percentage with inoperable lesions will be high. Accordingly, we must continue our campaign to get the patient to the operating room as soon as possible after onset of symptoms. Actually in a study we recently made in our hospital in patients with carcinoma of the colon, the average duration of symptoms before the patient came to us was I I months.

Superiority of Results in Asymptomatic Patients. -The programme of the 1959 annual meeting of the American Cancer Society was devoted to the role of early detection of cancer. Several presentations were made indicating the great value of operating on patients in the asymptomatic stage or soon after onset of symptoms. To obtain patients in the asymptomatic stage some type of detection examination must be carried out. Thi can be carried out in the doctor's office or i regular detection centres. Obviously, it would be desirable to have the bulk of these patients: screened by the doctor in his office.

In 8I naval personnel with cancer of the lung Brown (1960) reported that $69 \%$ of the cases discovered by detection examinations were re $\overline{\bar{D}}$. sectable whereas only $49 \%$ of the patients coming to the doctor because of symptoms were resectable Moreover, the five-year survival rate of the patients operated on for asymptomatic lung cancep was $20 \%$ compared to 5 to $10 \%$ for the patients diagnosed by routine methods. In a study of I, 000 patients with cancer of the breast, Urba (1960) reported a five-year survival rate of ove 3 . $69 \%$ in asymptomatic patients compared to only $44.8 \%$ in patients with symptoms or a known mass for a variable length of time preceding operation. In a study of 935 patients examined iro the University of Minnesota Detection Cente over a period of I I years, Shahon and Wangenstees ( 1960 ) reported a five-year survival rate of $26.3 \%$ for the symptomatic group of gastrointestinat cancer compared to $62.5 \%$ for the asymptomatie group. From that clinic Hitchcock and Aust (1955) reported that six of nine patients nots asymptomatic cancer of the stomach were ate after five years whereas only one of the five patiegite with symptomatic cancer of the stomach was alive after five years. In patients with cancer of the stomach they found achlorhydria and $x$-rap examinations were the two most valuable manifes tations or mechanisms in establishing the diagnosis $\overrightarrow{0}$

In a series of 106 patients with malignant ulce $\bar{B}$ of the stomach which were thought clinically to. be benign, but operated on, Brown, Cain an $\vec{\Phi}$. Dockerty (I96I) from the Mayo Clinic found that the five-year survival rate in the patients having. early operation was $92 \%$, whereas the five-yeas survival rate in patients having late operatio (i.e. after three or more months' study and con servative treatment) was only $60 \%$. These figures would appear to be significant particularly because the patients with no clinical or roentgenologies evidence of malignancy would obviously be the ones on which operation would be postponed Accordingly, it would appear that the grou having late operation would be the most favour able group from the standpoint of invasiveness of lack of it. In this series, the resectability rate was $86.8 \%$, which is much higher than the resecta? bility rate for the hyperplastic type of gastri岛 carcinoma.

The Role of Cytology in Early Diagnosis.-ThE epochal discovery of the staining process by Papanicolaou (1954) has exerted a tremendoue्क 
beneficial influence on the five-year survival rate of numerous types of cancer. Here again the detection examination becomes a vital procedure. Tumours of the uterus, lung, bladder, and intestinal tract can be diagnosed by smears of secretions, and exfoliative cytology. Cancer of the cervix and the body of the uterus have received most attention justifiably because of the accuracy of this type of examination. It would appear that after adequate technicians are available and the vast majority of women past the age of 30 could be induced to have vaginal smears done at routine intervals, deaths from cancer of the cervix could be reduced to a small fraction of the number reported at the present time. We can now say that the pathologists are adequately trained in this method of staining and diagnostic methods, but that the number of trained technicians is so small that only a small portion of the female population could be examined by this procedure at the present time.

Diagnosis of carcinoma of the lung by smears and the Papanicolaou stain are already of more value than biopsy during bronchoscopy because so many of the bronchial tumours are located in the bronchi invisible to the bronchoscopist. Many workers report favourable results in obtaining smears from the stomach and colon, but the number of bacteria, particularly in the colon, jeopardises the value of exfoliative cytology in this area to some extent because cancer cells are so readily destroyed by bacteria.

\section{Preventive Measures}

As stated previously, it appears that the greatest improvement in surgical treatment of cancer now lies in the adoption of improvements in technique which would minimize dissemination of cancer. We are aware of the fact that cells can be implanted into wounds and that cancer cells can be disseminated systemically from the tumour itself during operation. We, of course, realize that in the early stages of cancer all of these desquamated cells are probably killed by the host's resistance. As the weeks and months go by, resistance is decreased. It seems obvious that there comes a day when many of these cells which are desquamated from the tumour by lymphatics or vascular channels will survive and grow into metastases. As the disease becomes more advanced, it appears that the patient's resistance may be so low that most desquamated cells would survive. It is our contention that many preventive measures can be adopted to improve results, largely by limiting the desquamation of cells. A study of the literature reveals that local recurrence in the wound following operation for cancer of the breast (see Fig. 2) develops in

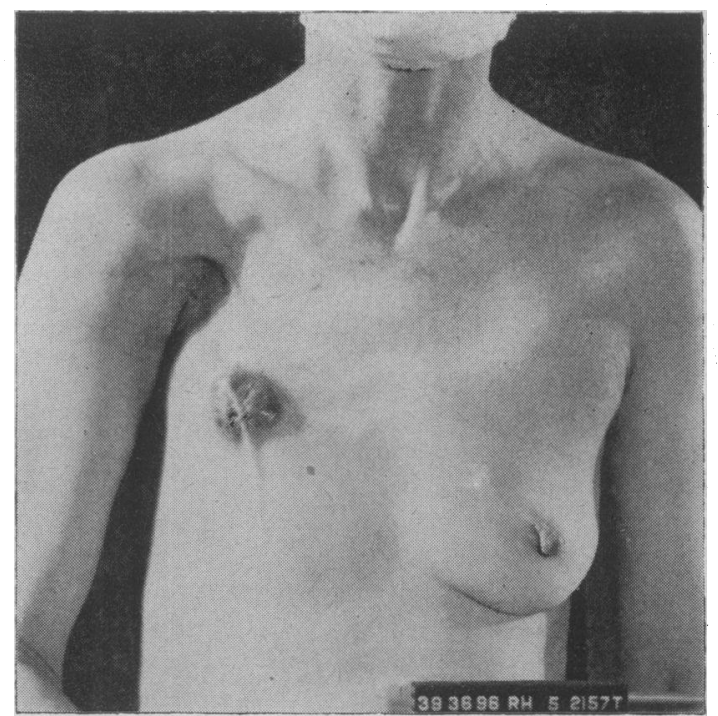

Fig. 2.-Four years previous to the time this photo was taken a radical mastectomy was performed. Six months ago a small nodule developed in the scar of the incision. It was removed with a wide margin, and a skin graft applied. The microscopic section showed it to be an adenocarcinoma similar to the primary. With little doubt this was an implant, the cells lying dormant for three and one-half years.

10 to $15 \%$ of patients (White, 1946; Taylor and Wallace, 1947; Robnett, Jones and Hazard, I950; Haagensen, 1956). In patients with cancer of the oral cavity having radical neck operations, the local recurrence rate is much higher (Wilkins, 1956; Harrold, 1952), varying between 20 and $35 \%$. We must make all effort to reduce the desquamation of cells and the possibility of implantation in tissue representing fertile soil.

\section{Precautions Before Operation}

During examination of the patient the tumour should be examined gently lest cells be dislodged into the lymphatics or vascular channels. The classical experiments reported by Tyzzer in 1913 emphasized the importance of this precaution. Working with the waltzing mouse tumour, he did not find metastases in the control mice before the 39th day. However, in mice having massage of their tumour $80 \%$ of the mice had pulmonary

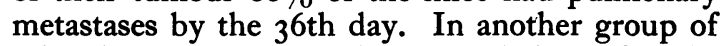
mice killed 46 days after inoculation of cells, $66 \%$ having massage of their tumour had metastases to the lung or other organs, whereas only $27 \%$ of control mice not having massage of their tumour and sacrificed at the same period had metastases. Marsh (1927) performed a similar experiment in albino mice, utilizing a spontaneous 
epithelial (breast) tumour. In 50 mice having massage of their tumour gross pulmonary metastases were noted in $62 \%$ at death, whereas in 459 control mice having no massage of their tumour only $40 \%$ had pulmonary metastases. Tyzzer also reported that incision or incomplete removal of the tumour resulted in an increased growth of metastases although they did not increase in number.

All of us who are engaged in teaching have been apprehensive about examination of a tumour (which might be malignant) by numerous students. Many of us have adopted the principle of not having more than one student examine these tumours. This precaution seems valid to adopt as a routine because we do not know whether or not the patient's resistance is sufficient to kill these cells which might be desquamated by the manipulation. We realize that the actual cause of death in advanced cancer is due to this vascular spread in the majority of patients, exceptions being limited primarily to neck tumours which notoriously remain local and often kill by compression or malnutrition.

Minimal Use of Biopsy in Certain Tumours.There is considerable controversy as to the danger of biopsy from the standpoint of dissemination of cancer cells. Yet, we realize that the majority of operations for tumours cannot be carried out correctly unless we have a positive diagnosis. Several workers have carried out experiments in animals trying to ascertain whether or not incision or biopsy would result in an increase in metastases or an increase of growth. The result of these experiments are variable; some claim detrimental effects of the biopsy, whereas others do not. Data from both sides of the controversy were collected by Hellwig (1932). He noted that Bloodgood and Ewing were convinced that a biopsy in certain tumours, such as bone sarcomas, were dangerous from the standpoint of possible dissemination of cells. The present authors are quite convinced that biopsy of surface lesions, such as carcinoma of the rectum, and many types of squamous cell lesions are harmless. However, we are apprehensive about the possible harmful effects of an incisional biopsy with closure of the wound, or of an aspiration biopsy of tumours which are enclosed by a capsule or limiting membrane so that the intra-tumour pressure might be greater than the pressure in the veins. This variation in pressure might allow intravasation of cancer cells into the venules because of the pressure within the tumour itself. Actually there are innumerable reports of tumours growing out through the track made by a needle biopsy, especially in cancer of the thyroid and breast. Tumours of the testicle would also represent examples of those with increased intra- tumour pressure. In general, any fast-growiri tumour might have a pressure within it which would be higher than the pressure in the vessels?

Sayago and Sirebrenick (1959) have conducted a study comparing the five-year survival results if patients with and without delay between biops $\vec{*}$ and the definitive operations for cancer of the breast. In 33 patients with an average delay of $3 \frac{9}{3}$ days between biopsy and the radical mastectom涫. the five-year survival rate (without evidence of disease) was only $27.3 \%$, whereas it was $84.7 \%$ (alive and free from disease) in 39 patients having radical mastectomy immediately after biops $\overrightarrow{6}$ Analyzing the patients with cancer of the breast in our clinic who had a biopsy elsewhere more thag 24 hours before admission Davis (1957) noted \& much higher five-year survival rate in patien having excisional biopsy than in patients having. incisional biopsy or operation biopsy.

Improving Operability to a Maximum Degreat To avoid an unduly high mortality rate following operation, every effort should be made to improvङ the patient's reserve and thus improve his operability (Harridge and Cole, I960). We have already called attention to the importance of correction of malnutrition because in our opinion this complication is tolerated so poorly, especially by elderly people. All other complications shoß18 be corrected if possible. It is admitted at numerous complications will be uncorrectaEle Under such circumstances, it may be necessir to modify the type of operation so that th expected mortality rate will not be prohibitive.

\section{Preventive Measures During Operation}

During the operation numerous things can bo done which will minimize dissemination of canceg cells.

Measures to Prevent Contamination of the Wound. There are innumerable reports in the medical literature giving examples of almost at conceivable types of implantation and recurrences. Examples of this are implants in the wound of patients having radical mastectomy, implants in celiotomy wounds, implants in the perineur following resection of the rectum, implants in the donor site as well as the graft site in patients havin skin grafts following radical mastectomy, etc. Thre cells may be disseminated into the wound by several mechanisms. In the first place, the ins cision around the tumour might cut across the lymphatics or venules containing tumour cells These cells might then be dislodged into the wound. We must admit that on certain occasions it will be very difficult to distinguish between $: \frac{5}{d}$ local implant and recurrence due to unexcised malignant tissue. If the recurrence is fixed to deeper tissue, there is a strong indication that it 
due to failure to resect all of the original tumour. On the contrary, if the nodule is freely movable and near the surface without evidence of tumour in deeper structures, there is a strong probability the recurrence is due to an implant. It is important to make this differentiation since operation will be indicated in most patients having a recurrence, whereas operation would seldom be indicated if the recurrence is due to inadequate excision of tissue at the time of the original operation.

Destruction of the Surface of Ulcerated Tumours. The greatest need for this precautionary measure to destroy the surface of ulcerated tumours would be in patients with oral cancer. This need becomes obvious because the line of excision is so close to the ulcerative lesion in the mouth, and because cells may be desquamated from the ulcer, thereby being implanted in the wound. From reports in the literature, it is obvious that cancer cells can migrate and contaminate tissue almost as effectively as can bacteria. The surface of the wound can be destroyed by one of several mechanisms, but it would appear that destruction by heat would be preferable to destruction by chemicals because heat would penetrate more uniformly than would a chemical.

Protective Pads on Wound Edges and Around the Tumour. As rapidly as the incision through tissue is made during the operation, the wound edges should be covered with gauze pads to protect them from possible cell contamination. This precaution would likewise protect the wound against bacteria. When the contamination from cancer cells appears to be minor in character, wet gauze is desirable because it is less damaging to raw tissue. However, if the source of cell contamination is major, such as would exist in a frank ulcerating lesion, the gauze pad should be dry to minimize transportation of cancer cells through the wet gauze. Such pads should be changed frequently, although, when the tumour itself is surrounded with the pad, it is perhaps desirable to cover it with a thick layer of gauze to prevent exudative material from soaking through and perhaps contaminating gloves, instruments, etc. Actually, Pomeranz and Garlock (1955) have recommended that these pads be covered with impervious material and anchored so that cancer cells cannot migrate through the gauze.

Change Instruments and Gloves Frequently. Several years ago Saphir (1936) called attention to the danger of transplantation of cancer cells from scalpel blades into the wound. Obviously the possibility of transfer of cells by instruments and gloves is just as important. Accordingly the surgeon must use caution at all times throughout the operation to avoid this possible source of contamination. No instruments coming in close con- tact with the tumour should be used a second time without sterilization. As indicated later, these precautions are much more essential when a biopsy is performed just preliminary to a definitive operation.

If a Biopsy is Performed and is Positive, a Definitive Operation should be carried out immediately if possible. Because of the possibility that a biopsy of a malignant tumour might disseminate tumour cells locally, it is rather obvious that the definitive operation for removal of the cancer should be done immediately thereafter if the biopsy is positive. This is particularly true if an incisional biopsy has been performed. Even though the biopsy has been excisional, the line of excision is so close to the tumour that cells in adjacent lymphatics and venules might escape into the wound during the process of excision of the tumour for biopsy. If sufficient days intervene between the biopsy and definitive operation, there is probably more danger of implantation and recurrent growth than if the definitive operation is done at the time of the biopsy. This procedure of performing a definitive operation immediately after the biopsy is dependent upon the willingness of the pathologist to perform frozen sections and to accept these diagnoses as being final. However, since surgical pathology techniques have improved so much during the past few years, most pathologists now appear willing to accept their own frozen section diagnoses because the frozen sections now bear such close resemblance to paraffin block sections.

Proper Use of Wash Basins. During a radical operation for cancer, instruments and the surgeon's gloves become contaminated with cancer cells on numerous occasions. Since the surgeon does not know when his gloves or instruments are contaminated, they should be washed frequently in a wash basin containing an anti-cancer solution. However, as indicated in the preceding section, gloves and instruments must be changed if the possibility of contamination is fairly strong. Although this extensive use of wash basins would no doubt minimize transfer of cells from gloves and instruments into the wound, it would not completely eliminate them, as is emphasized by a case report by Brandes, White and Sutton (1946). In this case report the cells were presumably transferred from the wash basin to the donor site, as indicated by a recurrence in this area three months after operation.

Irrigation of the Wound at the End of the Operation. Numerous investigators have reported can cer cells in the wound at the end of radical operations for cancer. Although it is not yet determined how many of these cells which dislodge into the wound at the time of operation will grow, it 
TABLE I

EXPERIMENTAL IRRIGATION OF WOUNDS INOCULATED With Cancer Cells (Walker 256) One Hour PREVIOUSLY

(After McDonald, Gines and Cole, in Arch. Surg., 1960)

\begin{tabular}{|c|c|c|}
\hline & $\begin{array}{l}\text { No. of } \\
\text { Rats }\end{array}$ & $\begin{array}{c}\% \text { Tumour } \\
\text { Growth }\end{array}$ \\
\hline Control (no irrigation) & 28 I & 95 \\
\hline Saline, isotonic. . . & 32 & 100 \\
\hline Oxytetracycline $\quad \ldots$ & 30 & 100 \\
\hline Distilled water .. & Io & 100 \\
\hline Heparin, 10 $\mathrm{mg} . \% \quad \ldots \quad \ldots$ & I0 & 100 \\
\hline Saline, $3 \% \quad \ldots \quad$.. & $3 \mathrm{I}$ & 90 \\
\hline $\begin{array}{c}\text { Monoxychlorosene } \\
\text { tin, } 0.5 \%\end{array}$ & & 86 \\
\hline 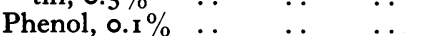 & 36 & 86 \\
\hline Sulfadiazine, sodium, I gm. \% & 30 & 83 \\
\hline $\begin{array}{l}\text { Chloroazodin (Azochloramide), } \\
0.05 \mathrm{mg} . \% \text { (wound slough if } \\
\text { higher concentration) }\end{array}$ & & 80 \\
\hline Benzalkonium (Zephiran) & & \\
\hline 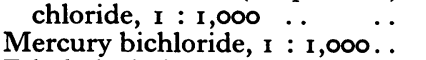 & $\begin{array}{l}35 \\
30\end{array}$ & $\begin{array}{l}71 \\
66\end{array}$ \\
\hline $\begin{array}{l}\text { Ethyl alcohol, 95\% } \\
\text { Monoxychlorosene, } 1 \%\end{array}$ & 7 & 57 \\
\hline $\begin{array}{c}\text { Monoxychlorosene, r.5\% } \\
\text { toxic for clinical use) }\end{array}$ & 30 & $\begin{array}{l}40 \\
36\end{array}$ \\
\hline $\begin{array}{l}\text { Strong iodine solution U.S.P. } \\
\text { (Lugol's solution) (half } \\
\text { strength) }\end{array}$ & 30 & 30 \\
\hline $\begin{array}{l}\text { Sodium hypochlorite, unbuf- } \\
\text { fered, } 0.5 \% \ldots\end{array}$ & & \\
\hline $\begin{array}{l}\text { Formaldehyde, } 0.3 \% \text { (too toxic } \\
\text { for clinical use) }\end{array}$ & 50 & 13 \\
\hline $\begin{array}{l}\text { Formaldehyde, } 0.4 \% \text { (too toxic } \\
\text { for clinical use) }\end{array}$ & 50 & 12 \\
\hline Styrlquinoline, ro mg. \% _. & 52 & 10 \\
\hline $\begin{array}{l}\text { Styrlquinoline, } 15 \mathrm{mg} . \% \\
\text { Formaldehyde, } 0.5 \% \text { (too toxic }\end{array}$ & 44 & 9 \\
\hline $\begin{array}{l}\text { for clinical use) } \\
\text { Sodium hypochlorite, } \quad 0.5 \%\end{array}$ & 39 & 8 \\
\hline $\begin{array}{l}\text { buffered to } \mathrm{pH} 9.0 \\
\text { Monoxychlorosene, } \quad 2 \%\end{array}$ & 56 & 8 \\
\hline $\begin{array}{l}\text { toxic for clinical use) } \\
\text { Mechlorethamine (nitrogen }\end{array}$ & 107 & 6 \\
\hline $\begin{array}{c}\text { mustard), } 2 \text { mg. } \% \ldots \\
\text { Mechlorethamine, } 1 \text { mg. } \%\end{array}$ & $\begin{array}{l}84 \\
54\end{array}$ & $\begin{array}{l}4 \\
4\end{array}$ \\
\hline
\end{tabular}

appears obvious that we should try to minimize this type of dissemination. We (McDonald, Gines and Cole, 1960) have conducted extensive experiments on the efficiency of irrigation of wounds in destroying cancer cells inoculated into them. In rats having wounds inoculated one hour before irrigation with various anti-cancer solutions it was found that certain agents are quite effective in destroying the cancer cells. For example, in control rats not having irrigation, growth of inoculated cells developed in $95 \%$ of the animals. The most effective agents used by us up to date have been nitrogen mustard (2.5 mg. per cent.) and sodium hypochlorite $(0.5 \%)$ buffered to 9.0 . The recurrence rate utilizing nitrogen mustard was $4 \%$ and for sodium hypochlorite it was $8 \%$ (see Table I). However, as stated above, we do not have proof that these irrigations are effective in human beings, but since the procedure is performed so simply we are of the opinion that the 3 method should be tried. We are likewise convinced $\stackrel{2}{\square}$ that if it is used the irrigation should be carried out $C$. for at least four minutes.

Prevention of Implants of Cells into the Suture Line Following Resection of the Intestine for Cancer. Several years ago three different groups (Morgan $\frac{\bar{c}}{\bar{N}}$ and Lloyd-Davies, 1950; Goligher, Duke and $\frac{\widehat{\sigma}}{\overrightarrow{0}}$ Bussey, 1951; Cole, 1952) became apprehensive $\cong$ about the number of recurrences found in the $\%$ suture line following resection of the colon for $\overrightarrow{0}$ malignant disease. Each group developed a procedure of their own to prevent these recurrences. Morgan and Lloyd-Davies (1950), as well as Goligher and associates (195I), irrigated the $\frac{0}{3}$ rectum with a solution of $I: 500$ bichloride of mercury after a clamp had been placed on the rectum. To prevent this possible contamination $\overrightarrow{0}$ we (Cole, 1955) have utilized ligation of the lumen of the colon (see Fig. 3) several inches $\frac{\omega}{\sigma}$ proximal and distal to the tumour as soon as o operability has been determined. After the bowel had been resected we then irrigate (see Fig. 4)

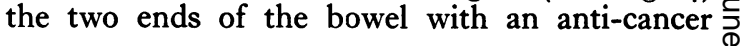

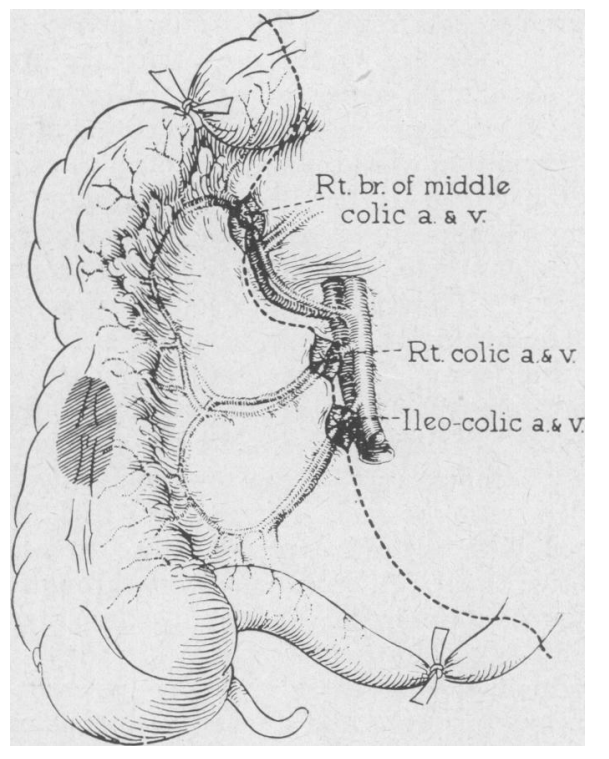

FIG. 3.-We recommend ligation of the intestine several inches above and below the tumour to prevent local implantation of malignant cells into the suture $N$ line during resection; whenever possible the vascular trunk (artery and vein) supplying the tumour area should be ligated as soon as resection 0 is decided upon, and before operative manipulation is begun; this should minimize the possibility of detachment of malignant cells from the invaded veins within the tumour during operation, and their transportation to distant organs. (After Cole et al. in F. Amer. med. Ass. (1954): 155, 1549. 


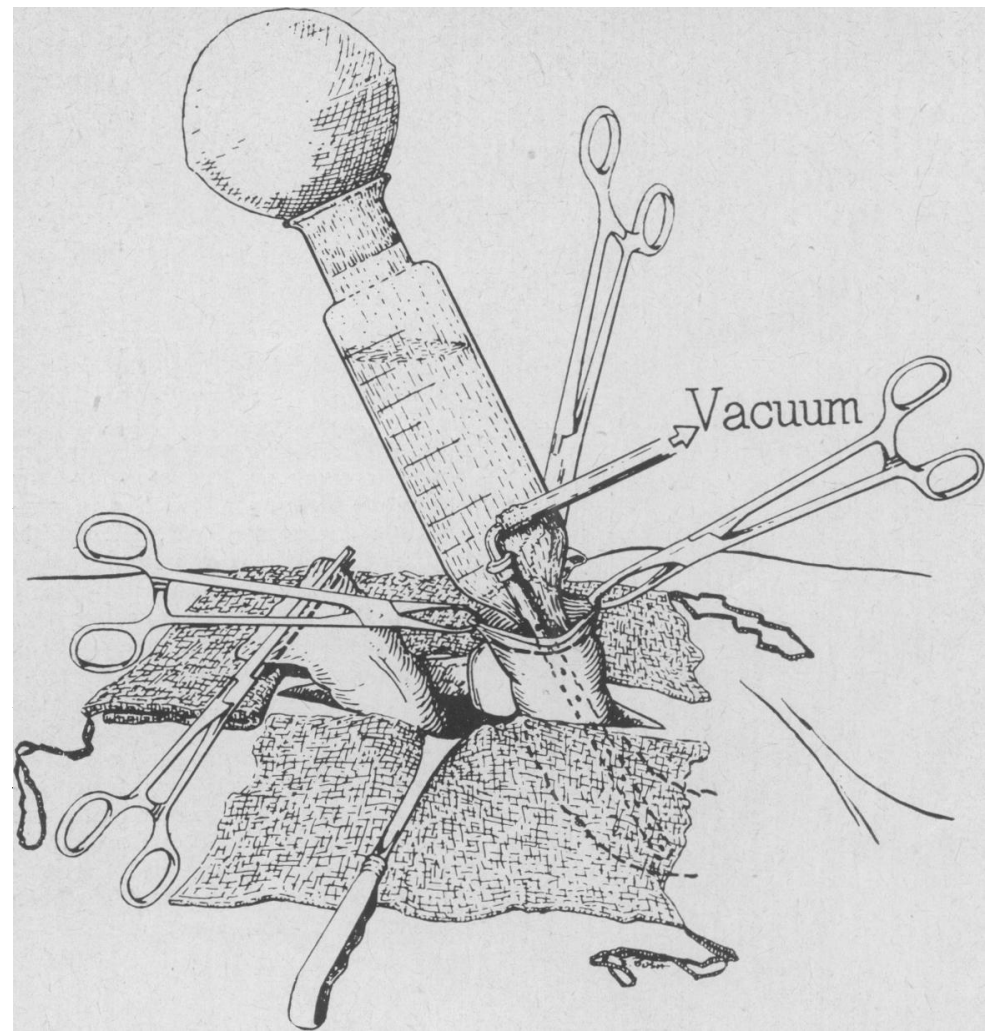

FIG. 4.-After the bowel and mesentery are resected, each end of the bowel is irrigated thoroughly for three to five minutes; at present we are using $0.5 \%$ sodium hypochlorite, buffered to a pH of 9.0. After irrigation, a small segment is cut off each end to minimize the possibility that cells were implanted into these ends when they were cut. (After Cole in Arch. Surg. (1952): 65, 264.)

agent (e.g. sodium hypochlorite $0.5 \%$ buffered to a $\mathrm{pH}$ of 9.0 ).

Before utilizing precautions Morgan and LloydDavies (1950) reported a recurrence rate of $24 \%$ following anterior resection. However, this was in a small series and a bigger series would probably correspond more closely to the percentage of $11 \%$ reported by Goligher and associates and $10.9 \%$ reported by us. Since beginning these precautionary measures all three groups have practically eliminated recurrences in the suture line.

Measures to Prevent Systemic Dissemination of Cancer Cells of the Wound During Operation. Unfortunately, there are several possible mechanisms by which cells may be disseminated systemically during the operation. With precautions many of these can be eliminated or sharply minimized.

The Danger of using Soap and Water Preparation of the Skin Preliminary to Operation. In our opinion the soap and water preparation of the skin of patients in the operating room (see Fig. 5) is a dangerous procedure because of possible vascular dissemination of cells during the procedure. It would appear that the vigorous scrubbing which is part of the soap and water preparation might dislodge cells growing into veins or adjacent to veins, and force them outward into the systemic circulation. Again, we are not certain how many of these cells will survive and grow into metastases. Nevertheless, since we know that the great majority of patients dying from their cancer have venous metastases in lungs, liver, bone, etc., it would appear we should use all precautions possible in minimizing this danger. There are so many effective antiseptics that it would appear highly desirable to utilize one of these agents in preference to soap and water preparation of the skin when a nodule (possibly malignant) is present.

Gentleness in Technique During the Operation. From the standpoint of good wound healing, surgeons have recognized for years that rough handling of tissue results in impaired healing of the wound. It appears also that rough handling of tissue may increase the possibility of dissemination of cancer cells into the lymphatics or veins. Many of these precautions have been emphasized very effectively by Meyer (1953). The danger of unnecessary handling of the tumour has also been emphasized by Turnbull who reports that aspiration of venous blood draining from segments of bowel contaminated cancer of the colon yielded tumour cells in $28 \%$ of 35 patients having resection with the tissue handled in the usual manner. However, when the operation was performed 


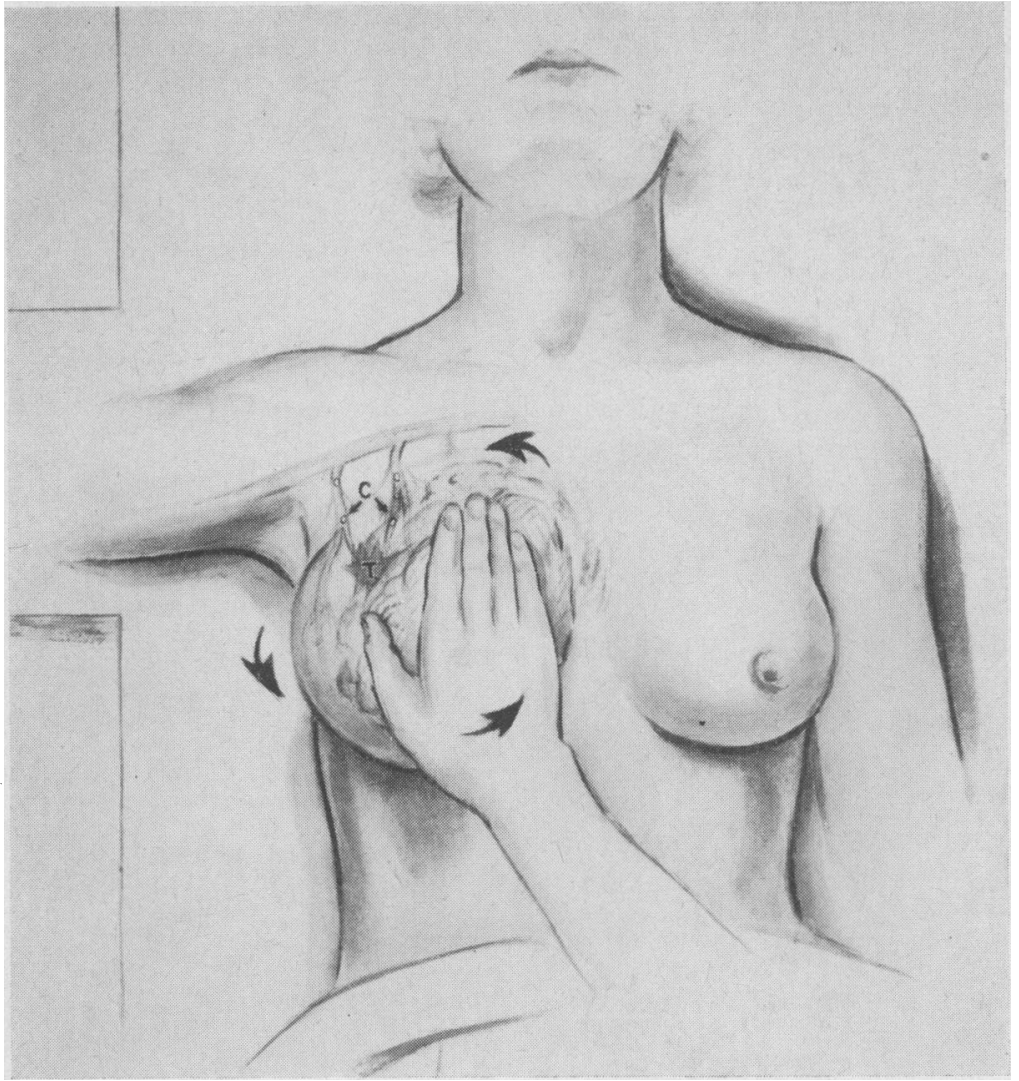

Fig. 5.-The use of soap and water for preparation of the skin in the $\vec{E}$ operating room is effective in prow viding an aseptic field, but shoulg not be used if the patient has $\infty$ palpable mass which could possibly. be malignant. Doing so createsi a definite danger of dissemination $V$ of cancer cells as illustrated in the diagram above, because of the् trauma inflicted by scrubbing process. $\mathrm{T}=$ tumour and $\mathrm{C}=\overrightarrow{\mathrm{O}}$ cancer cells which might be dis 0 lodged and find access into the venous system. (After Cole et al. $\overrightarrow{\text { }}$ in 'Dissemination of Cancer $E$ (196r): New York: D. Appletor? Century Crofts, Inc.)

without handling the tumour, cells were found in only $13 \%$ of 76 patients so treated.

To minimize rough handling of tissue, the incision should be placed strategically over the tumour so that retraction and manipulation of it can be minimized.

Ligation of Vessels Leading to and from the Tumour before the Operation is Begun. In previous publications (Cole, 1952; Southwick and Cole, 1955) we have emphasized the desirability of ligating the vascular trunks before operative manipulation is begun. It is true that surgeons have been utilizing this precaution in cancer of the breast and cancer of the neck; however, it appears to have been neglected in cancer of the colon where this procedure can be done so readily before operative manipulation is initiated (see Fig. 3). This precaution cannot be carried out as readily in patients with cancer of the rectum except that the superior rectal artery and vein can easily be ligated in the initial stages of the operation before attempt to mobilize the rectum is begun. The procedure can also be carried out very effectively in tumours of the stomach when they are operable. Ligation of the major vascular trunks will eliminate most of the blood supply, bu\& obviously numerous small collaterals will carry blood to and from the tumour until all portions of the bowel and mesentery are severed.

When operating on the right colon an incision? can be made through the peritoneum of the mesocolon and vessels palpated with the finger. Having. been identified they are ligated in mass, but liga $\frac{5}{5}$ tion proximal to the area will be carried out late as the final stage of the resection is terminatedo Ligation of the vascular trunks will also ligate many lymphatics through which cancer cells might be transported away from the tumour by manipulation during the operative procedure.

Measures to Facilitate Complete Removal of the Tumour. All effort must be made to remove the tumour completely. One of the precautions in this phase of the operation is wide removal of the tumour. By including much normal tissue with the tumour, we minimize the chance of escape of cells from severed lymphatics and veins. PerhapsD more important than that is the danger of leaving residual tumour unless wide excision is practised This wide excision can be accomplished quite readily in cancer of the breast, but not so effec $\frac{\rho}{8}$ 
tively in cancer of the neck because of anatomical limitations. There is considerable controversy regarding the amount of intestine which must be removed along with the gastrointestinal tumour. However, it is more important to obtain wide resection of the mesocolon than to remove a large segment of the bowel itself. One of the advantages of the removal of a segment of the colon is the decrease in number of cells within the lumen at the point of section; this would reduce the possibility of contamination at the suture line. Numerous investigators have shown that cancer of the bowel does not extend distally more than 2 or $3 \mathrm{~cm}$. into the lymphatics or adjacent tissue. Accordingly, there is not a strong indication for removal of a large amount of bowel distal to the tumour itself.

When there is doubt as to the limiting margin of the tumour, frozen section should be utilized to make certain all the tumour has been excised. This precaution is particularly important when operating on tumours which notoriously invade extensively through tissue planes. Carcinoma of the œsophagus, and to a lesser extent carcinoma of the stomach, are examples of tumours which invade widely through tissue planes. Accordingly, when operating on tumours of this type, a frozen section of the edge of the specimen is often necessary to prove all of the tumour has been excised.

Also important in obtaining complete removal of malignant tissue is the excision of the tumour in continuity. This would minimize the chance of residual tumour and likewise would minimize the possibility of dissemination by cutting through planes which might be involved with tumour. Nearly all surgeons practice this procedure in radical mastectomy and neck tumours. It is difficult to obtain excision by continuity in malignant disease of the extremities since the lymphatic nodes are often located so far away from the primary tumour. For example, excision in continuity could not be achieved in excising a melanoma of the finger since the axilla is so far away. However, when the primary tumour is located near the lymph nodes draining the area, excision by continuity is usually readily achieved.

\section{Use of Anti-Cancer Compounds at the Time of Operation as a Prophylactic and Adjuvant Procedure}

In 1956 we (Cruz, McDonald and Cole) reported the use of chemotherapeutic agents at the time of inoculation of cancer cells to prevent development of tumours. As soon as we noted that administration of anti-cancer agents, such as nitrogen mustard and ThioTEPA, would reduce the percentage of 'takes' in animals inoculated simultaneously with cancer cells (Walker 256 in rats) we began the use of this adjuvant measure in human beings with cancer of the breast, colon, rectum and stomach (Mrazek, Economou; McDonald, Slaughter and Cole, 1959). Two years later we joined the adjuvant group of the National Cancer Institute with patients having cancer of the lung and stomach, but retained our patients with cancer of the breast, colon and rectum in our own series because this series had been in existence for two years and we did not wish to discard these cases. In our patients with cancer of the breast we give a total dose of $0.4 \mathrm{mg}$. per kg. as a course dose, but as a precaution to prevent overdose we limit the total amount to $30 \mathrm{mg}$. for an adult. One-half of the dose is given intravenously on the day of operation before the patient leaves the operating room, one-quarter is given the following day, and one-quarter is given the next day. In 65 patients with cancer of the breast treated in this way there have been six deaths from cancer and I3 recurrences. In an equal number of patients utilized as controls not receiving the drug there have been 15 deaths from cancer and 20 recurrences. These figures appear to indicate quite clearly that the method is effective in cancer of the breast. The adjuvant group of the National Cancer Institute, composed of 20 or more different institutions utilizing ThioTEPA in this programme, reported (Moore, I960) figures on recurrences at the 1960 meeting of the American College of Surgeons which were quite superior to ours; however, their series has not been observed long enough to obtain data on deaths from cancer. In our series utilizing nitrogen mustard as a prophylactic or adjuvant measure at the time of the operation for cancer of the colon and rectum there has been no benefit. Accordingly, we are just beginning the use of a different agent in cancer of the colon and rectum. More time will be required to determine the exact benefit from this type of adjuvant therapy.

\section{Perfusion with Anti-Cancer Agents}

This procedure; which was initiated by Klopp, Alford, Bateman, Berry and Winship (1950), and improved by Creech, Krementz, Ryan, Keemtsma and Winblad (1959), by placing a tourniquet proximal to the area, occluding the artery and vein distally and connecting the vessels to an extracorporeal circuit consisting of ' arterial and venous pumps and a bubble oxygenator', offers considerable promise in the treatment of cancer. At the present time it is being used primarily in inoperable lesions of the extremities, or in patients who refuse amputation. However, it can be used in patients having malignant tumours of the shoulder, body wall and pelvis. When the procedure is used for lesions other than extremities the amount of 
leakage of the anti-cancer agent into the systemic circulation increases to a point that the advantages are minimized. When lesions of the extremities are perfused leakage can be reduced to no more than 5 or $10 \%$, thus making exposure of the tumour to the drug very intense. Creech has reported that aspiration of bone marrow from the sternum and iliac crest prior to the perfusion will allow a larger dosage by injecting the marrow into the patient several hours after the perfusion.

In a series of 145 patients treated by this method Creech and associates report the best results in patients with melanoma. Out of 29 patients with advanced melanoma the tumour remained quiescent in 21 following perfusion. In six there was a temporary response to treatment, although the lesion subsequently began to grow. Stehlin, Clark, White, Smith, Griffin, Jesse and Healey (1960), reporting on I 16 perfusions in heparinized patients, observed temporary benefit in 25 to $30 \%$ of their patients, most of whom had advanced tumours. As in prophylactic or adjuvant therapy, the effectiveness of this procedure is related to the relative efficiency of the drug itself. Actually tho drugs used currently in the treatment of cancer arहै not very effective from the standpoint of regressio of the tumour.

\section{The Need for Assay of the Tumour Against Anti-Cancer Compounds}

The anti-cancer compounds in use at the present time are not curative and are very in consistent in their action. For example, one agenf will cause a regression in some patients with cance of the breast and not in others. Likewise on agent may not be effective in one patient, whereas another will. Therefore it appears obvious that some method of testing cells from a given tumou $\vec{\tau}$ against various agents to find out which agent is the most effective is highly indicated. In fact, in this present state of effectiveness of the drugs there is. just as much reason for testing cancer cells against్ anti-cancer agents as testing bacteria against anti biotics. We (in association with G. O. McDonald $\Phi^{\circ}$ are carrying out experiments on this problem and hope that an effective method can be developed.

\section{REFERENCES}

Brandes, W. W., White, W. C., and Sutton, J. B. (1946): Accidental Transplantation of Cancer in the Operating Room, with a Case Report, Surg. Gynec. Obstet., 82, 212.

Brown, P. M., CaIn, J. C., and Dockerty, M. B. (I961): Clinically Benign Gastric Ulceration found to be Maligna at Operation, Ibid., $\mathbf{1 1 2}, 82$.

Brown, R. B. (1960): Value of Periodic Examinations in Detecting Early Lung Cancer, Postgrad. Med., $27,312$.

Cole, W. H. (1952): Recurrence in Carcinoma of the Colon and Proximal Rectum following Resection for Carcinoma Arch. Surg. (Chicago), 65, 264.

- McDonald, G. O., Roberts, S., and Southwick, H. W. (196r): Dissemination of Cancer. New York D. Appleton Century Crofts, Inc.

Creech, O., Krementz, E. T., Ryan, R. F., Reemtsma, K., and Winblad, J. N. (1959): Experiences with Isolationperfusion Technics in the Treatment of Cancer, Ann. Surg., 149, 627.

Cruz, E. P., McDonald, G. O., and Cole, W. H. (1956): Prophylactic Treatment of Cancer, Surgery, 40, 29r.

Davis, J. B. (1957): Carcinoma of the Breast, Arch. Surg. (Chicago), 74, 758.

Goligher, J. C., Dukes, C. E., and Bussey, H. J. R. (I95I): Local Recurrence after Sphincter-saving Excisions for Carcinoma of the Rectum and Rectosigmoid, Brit. F. Surg., 39, 199.

Griffin, G. D. J., Judd, E. S., and Gage, R. P. (1956): Carcinoma of the Right Side of the Colon; Operabilityo Resectability and Survival Rates, Ann. Surg., 143, 330.

HaAgensen, C. D. (1956): Diseases of the Breast, p. 628. Philadelphia: J. B. Saunders Company.

Harridge, W. H., and Cole, W. H. (r 960): Methods for Improving Operability in the Aged, F. Amer. Geriat. Soc.尹 8, 79 .

HarRold, C. C. (1952): Present-day Methods of Surgical Treatment of Intra-oral Cancer. Second National Cancer Conference Proceedings, pp. 444-455.

Hellwig, C. A. (1932): Biopsy in Tumours, Arch. Path. (Chicago), 13, 607.

Hiтснсоск, C. R., and Aust, J. B. (1955): Diagnosis of Asymptomatic Malignant Disease, Postgrad. Med., r7, 145 Klopp, C. T., Alford, T. C., Bateman, J. A., BerRy, G. N., and Winship, T. (1950): Intra-arterial Cancer Chemo-o
therapy with Methyl Bisamine Hydrochloride, Ann. Surg., 132, 81 1.

Marsh, M. C. (1927): Tumour Massage and Metastases in Mice, $\mathscr{F}$. Cancer Res., rr, Ior.
Mayo, C. W., and Fly, O. A. (1956): Analysis of Five-year Survival in Carcinomas of the Rectum and Rectosigmoid ${ }^{\circ}$

Surg. Gynec. Obstet., ro3, 94.
McDonald, G. O., Gines, S. M., and Cole, W. H. (1960): Wound Irrigation in Cancer Surgery, Arch. Surg. (Chicago), 슬
80, 920. MEYER, H. W. (1953): Technic of Radical Mastectomy with Reference to Extension of the Dissection to Mediastinal
and Cervical Nodes, N.Y. St. F. Med., 53, 2977. Moore, G. (1960): Chemotherapy of the Cancer Patient. Presented at the Annual Meeting of the American College ${ }_{\mathbb{C}}$
of Surgeons, October 10-14, I960.

Morgan, C. N., and Lloyd-Davies, O. V. (1950): Discussion on Conservative Resection in Carcinoma of the Rectum, Proc. roy. Soc. Med., 43, 701.

Mrazek, R., Economou, S., McDonald, G. O., Slaughter, D., and Cole, W. H. (r959): Prophylactic and Adjuvanto Use of Nitrogen Mustard in the Surgical Treatment of Cancer, Ann. Surg., I50, 745. 
MuSTARD, R. A. (1956): Carcinoma of the Esophagus: A Review of 38I Cases Admitted to Toronto General Hospital 1937-1953, inclusive, Ibid., 144, 927.

Papanicolaou, G. N. (1954): Atlas of Exfoliative Cytology. Cambridge, Mass.: Harvard Univ. Press.

Pomeranz, A. A., and GarLock, J. H. (1955): Postoperative Recurrence of Cancer of Colon due to Desquamated Malignant Cells, f. Amer. med. Ass., 158, 1434.

RoBnetT, A. H., JonES, T. E., and HAZARD, J. B. (1950): Carcinoma of the Breast: Recurrence and Survival in 203 Patients, Cancer (Philad.), 3, 757.

Saphir, O. (1936): The Transfer of Tumour Cells by the Surgical Knife, Surg. Gynec. Obstet., 63, 775 .

Sayago, C., and Sirebrenik, O. (1959): Surgical Biopsy as a Disseminating Factor in Breast Cancer, Acta Un. int. Cancr., 15, 116r.

Shahon, D. B., and Wangensteen, O. H. (1960): Early Diagnosis of Cancer of the Gastrointestinal Tract, Postgrad. Med., 27, 306.

Soutrwick, H. W., and Cole, W. H. (1955): Prophylactic Measures in Local Recurrence and Venous Metastases in Carcinoma of the Colon, Surg. Clin. N. Amer., 35, 1363.

Stehlin, J. S., Clark, R. L., White, E. C., Smith, J. L., Griffin, A. C., Jesse, R. H., and Healey, J. E. (i960): Regional Chemotherapy for Cancer: Experience with I 16 Perfusions, Ann. Surg., 157, 605.

Taylor, G. W., and Wallace, R. H. (I947): Carcinoma of the Breast: End Results, New Engl. F. Med., 237, 475.

Turnbull, R. B. Jr.: Personal communication.

Tyzzer, E. E. (1913): Factors in the Production and Growth of Tumour Metastases, f. med. Res., 28, 309.

Urban, J. A. (1960): Treatment of Early Cancer of the Breast, Postgrad. Med., 27, 389.

White, W. C. (1946): The Problem of Local Recurrence after Radical Mastectomy for Carcinoma, Surgery, $19,149$.

WILKINS, S. A. Jr. (1956): Evaluation of Surgical Failures in the Treatment of Cancer of the Gingiva. Third National Cancer Conference Proceedings, pp. 562-567. 